\title{
Microstructural Characterization of the Effect Cementation Treatment on Microalloyed Steel Boronizing
}

\author{
N. Lopez-Perrusquia ${ }^{1 *}$, M. A. Doñu-Ruiz ${ }^{1}$, G. J. Pérez Mendoza ${ }^{1}$, C. R. Torres San Miguel ${ }^{2}$. \\ 1. Universidad Politécnica del Valle de México, Grupo Ciencia e Ingeniería de Materiales, 54910, \\ Tultitlán, Estado de México \\ 2. Instituto Politécnico Nacional, ESIME-Zacatenco, Unidad Profesional Adolfo López Mateos Col. \\ Lindavista, CP 07340, Ciudad de México. México. \\ * Corresponding author: noeperrusquia@ hotmail.com
}

Thermochemical treatments have been implemented to expand the versatility of surface microstructural properties in microalloyed steel used in conditions of high temperatures, wear, corrosion, erosion, fatigue, and embrittlement hydrogen [1-2]. Thermochemical treatments are used as an alternative to improve surface properties. Pack Boriding in ferrous and nonferrous alloys can be carried out between temperatures of $1073 \mathrm{~K}$ and $1323 \mathrm{~K}$ [3] and Pack cementation is considered as an industrial coating technique, it typically requires process temperature of 1083-1223K. In the present study, the microstructure has been investigated the effect on cementation on microalloyed steel borided, also the nanohardness obtained in the coatings.

The microalloyed steel was studied with chemical composition; C-0.012, Mn-1.48, Si-0.27, P-0.012 S0.008, Al-0.039, Nb-0.041, Cu-0.006, Mo-0.032, Ti-0.009, V-0.048 (\% weight) and dimensions of 10 $\mathrm{mm} \times 7.5 \mathrm{~mm}$. Prior to the boriding process, the samples were sanded with 80 to 600 grade carbide abrasive paper and cleaned with alcohol. Dehydrated paste pack boriding [4], was carried out at $1273 \mathrm{~K}$ for $8 \mathrm{~h}$. After, samples of microalloyed steel borided were exposed to the cementation process by powder pack (charcoal, coke, sodium carbonate, barium carbonate, and calcium chloride) at $1173 \mathrm{~K}$ for $12 \mathrm{~h}$. In both processes, the treatments were carried out in a conventional furnace without the use of a controlled atmosphere, at the end of each process the cooling was at room temperature. The surface treated samples were cross-sectioned, mounted and prepared for metallographic preparation; the polished samples were etched in a $2 \%$ nital solution to observed the coatings. The microstructural characterization produced by the boride and cementation process were analyzed by Scanning Electron Microscope (SEM) with Energy Dispersive Spectroscopy (EDS) using JEOL 6010 LV, X-Ray Diffraction (XRD) with equipment Bruker D8 Advance and nanohardness was established by depth sensing instrument indentation testing using an ultra micro Hardness Tester DUH211s with indentation load of $100 \mathrm{mN}$.

Figure 1a shows the cross-sections of $\mathrm{FeB} / \mathrm{Fe}_{2} \mathrm{~B}$ formed on the surface of microalloyed steel and the cementation and $\mathrm{Fe}_{2} \mathrm{~B}$ coatings are observed in Figure $1 \mathrm{~b}$ with removing the $\mathrm{FeB}$ phase. The formation of $\mathrm{FeB}+\mathrm{Fe}_{2} \mathrm{~B}$ coatings and single $\mathrm{Fe}_{2} \mathrm{~B}$ coating were confirmed by $\mathrm{XRD}$, as shown in Figure $2 \mathrm{a}$ and Figure $2 \mathrm{~b}$, respectively. $\mathrm{Fe}_{2} \mathrm{~B}$ and $\mathrm{FeB}$ within the boride coating exhibit substantially different coefficients of thermal which cause microcracks in the interface $\mathrm{Feb} / \mathrm{Fe}_{2} \mathrm{~B}$, so the formation of the $\mathrm{FeB}$ coating is often considered undesirable. Moreover, in Figure $3 \mathrm{a}$ shows the image (SEM) of hardness tests on surface microstructural across Boronizing and Cementation process. A schematic representation of the load-displacement curves obtained in the Cementation/ $\mathrm{Fe}_{2} \mathrm{~B}$ coating is shown in Figure $3 \mathrm{~b}$. The values of nanohardness obtained in cementation coating were obtained from range of 738.3 to 762.523 $\mathrm{Hv}$ and the $\mathrm{Fe}_{2} \mathrm{~B}$ coating in the range of to 1223.46 to $1792.6 \mathrm{Hv}$. This paper presents a contribution in 
the modification of the microstructural and eliminate the FeB coating by the pack Cementation process, as well as enhance the mechanical surface on microalloyed steels for industrial applications.

References:

[1] Eric J. Mittemeijer, Marcel A.J. Somers, Thermochemical Surface Engineering of Steels, Elsevier Woodhead Publishing, (2015) p. 141-206.

[2] Kennedy, D. Proceedings of International Conference, Matrix Materials, Tribology and Processing: Grilex and Maric eds. Croatia, (2008), p 26-28.

[3] Kulka M. Trends in Thermochemical Techniques of Boriding. In: Current Trends in Boriding. Engineering Materials. Springer, (2018), p 17-98.

[4] M. A Doñu Ruiz, et. al, Thin Solid Films, 596 (2015), p.147-154.
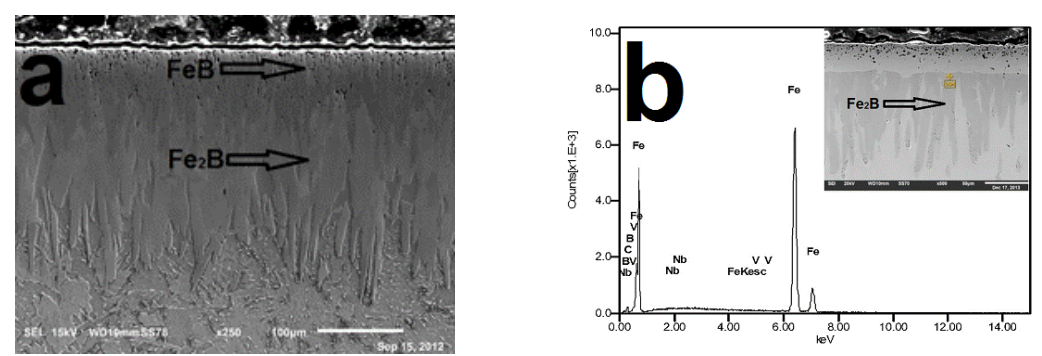

Figure 1. Microalloyed steel treatment a) SEM cross-sectional micrograph on sample borided and b) EDS spectrum of $\mathrm{Fe}_{2} \mathrm{~B}$ coating after the pack cementation.
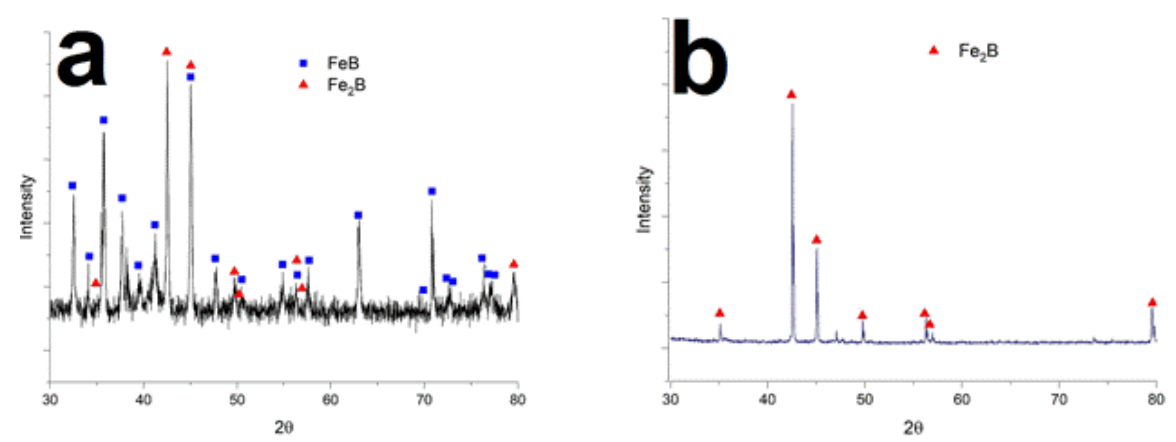

Figure 2. X-ray diffraction patterns on microalloyed steels a) borided coatings and b) effect of cementation on the boride coatings.
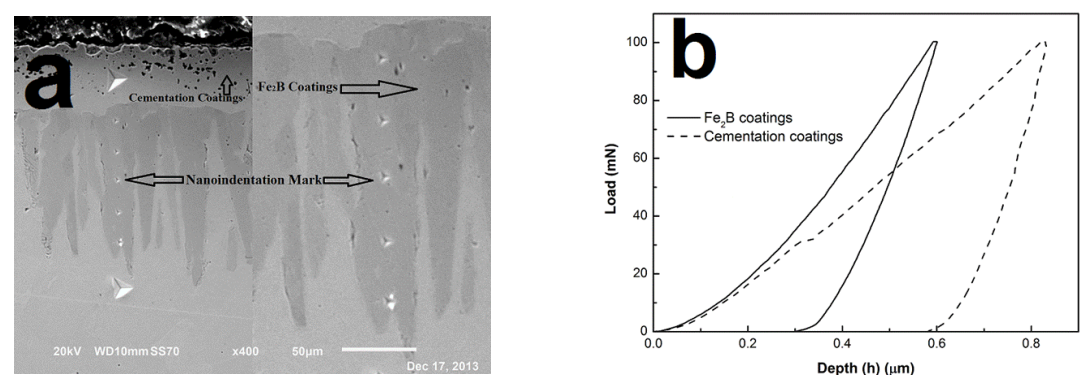

Figure 3. Nanoindentation performed across the boride-cementation coatings a) SEM image of nanoindentation and b) load-displacement curves obtained in $\mathrm{Fe}_{2} \mathrm{~B}$ and cementation coatings. 